\title{
Differences in the pharmacological activation of visual opsins
}

\author{
T. ISAYAMA, ${ }^{1}$ Y. CHEN,${ }^{2}$ M. KONO,${ }^{3}$ W.J. DEGRIP, ${ }^{4}$ J.-X. MA,${ }^{2}$ R.K. CROUCH,${ }^{3}$ \\ AND C.L. MAKINO ${ }^{1}$ \\ ${ }^{1}$ Department of Ophthalmology, Massachusetts Eye \& Ear Infirmary, Harvard Medical School, Boston, Massachusetts \\ ${ }^{2}$ Department of Cell Biology, University of Oklahoma Health Sciences Center, Oklahoma City, Oklahoma \\ ${ }^{3}$ Department of Ophthalmology, Storm Eye Research Institute, Medical University of South Carolina, Charleston, South Carolina \\ ${ }^{4}$ Department of Biochemistry, NCMLS, University of Nijmegen, Nijmegen, The Netherlands
}

(Received June 23, 2006; AccePted September 29, 2006)

\begin{abstract}
Opsins, like many other G-protein-coupled receptors, sustain constitutive activity in the absence of ligand. In partially bleached rods and cones, opsin's activity closes cGMP-gated channels and produces a state of "pigment adaptation" with reduced sensitivity to light and accelerated flash response kinetics. The truncated retinal analogue, $\beta$-ionone, further desensitizes partially bleached green-sensitive salamander rods, but enables partially bleached red-sensitive cones to recover dark-adapted physiology. Structural differences between rod and cone opsins were proposed to explain the effect. Rods and cones, however, also contain different transducins, raising the possibility that G-protein type determines the photoreceptor-specific effects of $\beta$-ionone. To test the two hypotheses, we applied $\beta$-ionone to partially bleached blue-sensitive rods and cones of salamander, two cells that couple the same cone-like opsin to either rod or cone transducin, respectively. Immunocytochemistry confirmed that all salamander rods contain one form of transducin, whereas all cones contain another. $\beta$-Ionone enhanced pigment adaptation in blue-sensitive rods, but it also did so in blue- and UV-sensitive cones. Furthermore, all recombinant salamander rod and cone opsins, with the exception of the red-sensitive cone opsin, activated rod transducin upon the addition of $\beta$-ionone. Thus opsin structure determines the identity of $\beta$-ionone as an agonist or an inverse agonist and in that respect distinguishes the red-sensitive cone opsin from all others.
\end{abstract}

Keywords: Rod, Cone, Rhodopsin, Transducin, Phototransduction

\section{Introduction}

In vertebrate rods and cones, light isomerizes the 11-cis retinal chromophore to the all-trans conformation, converting the visual pigment to a form that can activate the G-protein, transducin. Eventually, the pigment is phosphorylated and all-trans retinal dissociates, but opsin retains a weak ability to activate transducin, and that activity produces a $\mathrm{Ca}^{2+}$-dependent desensitization of the phototransduction pathway known as "pigment or bleaching adaptation" (reviewed in Ebrey \& Koutalos, 2001; Fain et al., 2001; McBee et al., 2001). Photoreceptors recover from pigment adaptation after replacement 11-cis retinal, supplied by pigment epithelial cells, regenerate the visual pigment, and quench opsin's activity.

A number of retinoids, including 11-cis retinol, 11-cis 13demethylretinal, and the truncated analogue $\beta$-ionone relieve pigment adaptation in red-sensitive (RS) cones (Jones et al., 1989; Jin et al., 1993; Corson et al., 2000), but intensify it in green-sensitive (GS) rods (Jones et al., 1989; Kefalov et al., 1999; Corson et al., 2000). Kefalov et al. (1999) proposed an "Opsin Hypothesis,"

Address correspondence and reprint requests to: Tomoki Isayama, Department of Ophthalmology, Massachusetts Eye \& Ear Infirmary, 243 Charles Street, Boston, MA 02114. E-mail: tomoki_isayama@meei. harvard.edu wherein a fundamental difference in the structures of rod and cone opsins causes retinoids to enhance rod opsin's activity, but quench that of cone opsin. Rods and cones, however, also express different transducins (Fung et al., 1992; Lee et al., 1992; Peng et al., 1992; Ong et al., 1995). So in an alternate "Transducin Hypothesis," different binding and activation requirements of rod and cone transducins could specify a retinoid as an agonist or an inverse agonist. These competing hypotheses were tested by applying $\beta$-ionone to partially bleached blue-sensitive (BS) rods and cones of salamander, which were previously shown to contain the same cone-type pigment, coupled to rod and cone transducins, respectively (Ma et al., 2001b). According to the Opsin Hypothesis, $\beta$-ionone should relieve pigment adaptation in BS rods and BS cones. On the contrary, the Transducin Hypothesis predicted that $\beta$-ionone should relieve pigment adaptation in BS cones, but intensify it in BS rods.

\section{Materials and methods}

\section{Animals}

Care and use of all animals conformed to the ARVO Statement for the Use of Animals in Ophthalmic and Vision Research and institutional guidelines. Larval tiger salamanders (Ambystoma tigrinum, Charles D. Sullivan, Inc., Nashville, TN) were main- 
tained in Holtfretter's solution with a twofold higher salinity on a 14-h light/10-h dark cycle at $16^{\circ} \mathrm{C}$ to $20^{\circ} \mathrm{C}$ for physiological experiments and on a 12 -h light $/ 12$-h dark cycle at $8^{\circ} \mathrm{C}$ to $10^{\circ} \mathrm{C}$ for all other experiments.

\section{Nomenclature}

For consistency, we define salamander rods and cones according to the color of light to which they are most sensitive; for example, GS rods contain rhodopsin and respond optimally to green light, while BS rods contain an SWS2 pigment which absorbs maximally in the blue. It should be pointed out that historically GS and BS rods are referred to as red and green rods, respectively.

\section{Single cell recording}

Salamanders were dark-adapted overnight, decapitated and retinal tissue prepared under infrared illumination (Makino et al., 1999). A piece of retina was mechanically dissociated, placed in the recording chamber and perfused continuously with Ringer's consisting of (mM): $108 \mathrm{NaCl}, 2.5 \mathrm{KCl}, 1.0 \mathrm{MgCl}_{2}, 10 \mathrm{HEPES}, 1.5$ $\mathrm{CaCl}_{2}, 0.02$ EDTA, 10 glucose, $7.5 \times 10^{-4}$ bovine serum albumin (BSA, Fraction V, $\gamma$-globulin-free, Sigma, St. Louis, MO), pH 7.6 at $20^{\circ} \mathrm{C}$ to $22^{\circ} \mathrm{C}$. Photocurrents were recorded from the inner segment of a single rod or cone with a suction electrode and a patch clamp amplifier (Axopatch 200A, Axon Instruments, Foster City, CA), low-pass filtered with an 8-pole Bessel $(30 \mathrm{~Hz},-3 \mathrm{~dB})$ and digitized at $400 \mathrm{~Hz}$. No corrections were made for the delay introduced by filtering. Cells were stimulated with light from a 75 $\mathrm{W}$ xenon arc lamp that passed through a six-cavity interference filter $(10 \mathrm{~nm}$ bandwidth at half-maximal transmission, Omega Optical, Brattleboro, VT) and an electronic shutter. A nominal duration of $22 \mathrm{~ms}$ was used for test flashes. Cells were identified by inspection and by their responses to flashes at $377 \mathrm{~nm}, 440 \mathrm{~nm}$, $500 \mathrm{~nm}$, and $620 \mathrm{~nm}$. The light was calibrated with a photometer (UDT 350, Graseby, Orlando, FL) through a 200- $\mu \mathrm{m}$ diameter pinhole (Melles Griot, Carlsbad, CA) placed at the level of the recording chamber.

$\beta$-Ionone was obtained from Sigma, re-distilled and dissolved in absolute ethanol. This stock was diluted with Ringer's to concentrations between 10 - and $40-\mu \mathrm{M}$ and a final concentration of ethanol $\leq 0.1 \%$. In control experiments, perfusion with $0.1 \%$ ethanol had no effect on the flash responses of any of the cells either before or after bleaching. $\beta$-Ionone was introduced through one channel of a theta tube. Ringer's ran through the other channel. A waste port positioned across from the theta tube established laminar flow from the two channels with little interfacial mixing. Because of the hydrophobicity of $\beta$-ionone, the actual concentration exiting the theta tube ranged from 5-17 $\mu \mathrm{M}$, as determined spectroscopically.

During an experiment, responses to test flashes were first recorded in Ringer's. Cells were then exposed to bright light: 2.2-4.0 $\times 10^{8}$ photons $\mu \mathrm{m}^{-2}$ at $600 \mathrm{~nm}$ for RS cones, 7.6-37.0 $\times$ $10^{7}$ photons $\mu \mathrm{m}^{-2}$ at $460 \mathrm{~nm}$ for BS cones, $1.4-3.4 \times 10^{7}$ photons $\mu \mathrm{m}^{-2}$ at $360 \mathrm{~nm}$ for UV-sensitive (UVS) cones, 9.4$11.0 \times 10^{7}$ photons $\mu \mathrm{m}^{-2}$ at $520 \mathrm{~nm}$ for GS rods, and $4.1-8.9 \times$ $10^{7}$ photons $\mu \mathrm{m}^{-2}$ at $400 \mathrm{~nm}$ for BS rods, in order to bleach a fraction of the pigment. The fractional bleach was calculated using the formula:

$$
F=1-\exp [-I P t]
$$

where $I$ is the light intensity in photons $\mu \mathrm{m}^{-2} \mathrm{~s}^{-1}, t$ is the duration of the bleach, and $P$ is the photosensitivity. Values used for $P$ were $\left(\mu \mathrm{m}^{2}\right.$ molecule $\left.{ }^{-1}\right): 5.4 \times 10^{-9}$ for GS rods and RS cones, $3.4 \times$ $10^{-9}$ for BS rods, $5.8 \times 10^{-9}$ for BS cones (Makino et al., 1991) and $9.3 \times 10^{-9}$ for UVS cones (Makino \& Dodd, 1996). The lower $P$ for BS rods than for BS cones adjusts for the reduced efficacy of bleaching at $400 \mathrm{~nm}$ compared to $460 \mathrm{~nm}$ (see above). The bleaching regimens used most frequently were chosen to reduce the post-bleach circulating current in each cell type by $30 \%$ to $50 \%$. Test flash responses were recorded after a minimal postbleach interlude of $30 \mathrm{~min}$ for cones and BS rods and $90 \mathrm{~min}$ for GS rods to allow for stabilization of the cell's condition. Additional flash responses were recorded while perfusing the cell with $\beta$-ionone and after being returned to Ringer's to wash away the $\beta$-ionone.

The stimulus-response relation was fit with the Hill equation:

$$
r / r_{\max }=i^{n} /\left[i^{n}+i_{0.5}^{n}\right],
$$

where $r$ is the response amplitude, $r_{\max }$ is the saturating response amplitude, $i$ is flash strength, and $n$ is the Hill coefficient. $i_{0.5}$, the flash strength at which one half of the maximal dark current was suppressed for each cell type, and $n$ were determined from the fit for each cell.

\section{Immunocytochemistry}

Retinas were fixed with $4 \%$ paraformaldehyde ( $\mathrm{pH} 7.4$ ) for 3-5 h. All procedures were performed at room temperature $\left(22^{\circ} \mathrm{C}\right)$ unless noted otherwise. Tissues were washed in Tris-buffered saline, and then incubated in $0.5 \% \mathrm{NaBH}_{4}$ for 5 min to minimize autofluorescence. After three washes, retinas were made permeable with $0.2 \%$ Triton $\mathrm{X}-100$ for $30 \mathrm{~min}$, then blocked overnight in $3 \%$ IgG-free BSA, $5 \%$ normal donkey serum at $4^{\circ} \mathrm{C}$. Tissues were incubated overnight at $4^{\circ} \mathrm{C}$ with rabbit anti-UVS cone opsin (1:200 dilutions, J.-X. Ma, unpublished data), washed three times, and subsequently incubated with Cy-5-conjugated donkey anti-rabbit IgG (1:100 dilution) for $1 \mathrm{hr}$, followed by three more washes. Retinas were transferred to rabbit anti-RS cone opsin (CERN 956, 1:100 dilution) (Vissers \& DeGrip, 1996) conjugated with Alexa Fluor 568 (Molecular Probes, Eugene, OR) for 1.5 h. All tissues were incubated overnight in rabbit $\gamma$ globulin serum at $4^{\circ} \mathrm{C}$, and washed 5 times. Retinas were subsequently stained with FITCconjugated rabbit anti-cone transducin $\alpha$-subunit (TA-2, 1:300 dilution) (Ryan et al., 2000) for $2 \mathrm{~h}$, washed three times, and incubated for $5 \mathrm{~min}$ in normal rabbit serum. Tissues were then incubated in Cy-2-conjugated monoclonal mouse anti-FITC (1:100 dilution, Jackson Immuno Research Laboratories, Inc., West Grove, PA) for $1.5 \mathrm{~h}$ to enhance the signal for anti-cone transducin labeling. Tissues were washed several times in buffer, fixed in $4 \%$ paraformaldehyde for $15 \mathrm{~min}$, washed once in buffer and once in distilled water. Finally, tissues were flattened on slides, treated with Prolong anti-fade solution (Molecular Probes) and cover slips were added.

Other retinas were used to test for the co-localization of rod and cone transducins. After blocking non-specific labeling (see above), retinas were incubated with FITC-conjugated rabbit anti-rod transducin (TA-1, 1:300 dilution) (Ryan et al., 2000) and biotinconjugated TA-2 (1:300 dilution) in 3\% BSA for $2 \mathrm{~h}$. Tissues were washed three times, then incubated with Texas Red-conjugated streptavidin (1:50 dilution) and FITC-conjugated anti-FITC (1:50 dilution) in $1 \%$ BSA for $1 \mathrm{~h}$. After washing in buffer and once in distilled water, retinas were mounted on slides as described earlier. 
Labeled tissues were viewed with a laser confocal microscope (Carl Zeiss Inc., Jena, Germany) and an integrating CCD camera (CCD100, Dage-MTI, Michigan City, IN). Images were collected with a Dual Pentium Pro 200 Imaging workstation (Dell Computers, Round Rock, TX) equipped with a Flashpoint 128 capture board (Integral Technologies, Indianapolis, IN), and processed with LSM 5 Image Examiner software (version 5.0, Carl Zeiss). The resultant images were pseudocolored and merged as a color montage.

\section{Activation of recombinant salamander pigments}

Methods for expressing salamander opsins in COS cells, preparing membranes, and purifying transducin from bovine retina were described previously (Baehr et al., 1982; Wessling-Resnick \& Johnson, 1987; Robinson, 2000; Das et al., 2004). Transducin activation was evaluated using a GTP $\gamma \mathrm{S}$ binding assay (Robinson et al., 1992; Robinson, 2000). The reaction mixture consisted of (mM): 10 MES, 1 Tris buffer (pH 6.5), $100 \mathrm{NaCl}, 5 \mathrm{MgCl}_{2}, 1$ DTT, 0.002 transducin, $10 \%$ glycerol (v/v), 5-50 $\times 10^{-6}$ opsin, and $0.003\left[{ }^{35} \mathrm{~S}\right]-\mathrm{GTP} \gamma \mathrm{S}(3.3 \mathrm{Ci} / \mathrm{mmoL})$. Immediately prior to the start of the assay, $1 \mu \mathrm{L}$ ethanol alone or containing 11-cis retinal (10 $\mu \mathrm{M}$ final concentration) or $\beta$-ionone (100 $\mu \mathrm{M}$ final concentration) was added. Ten microliter aliquots were spotted at $1 \mathrm{~min}$ intervals onto nitrocellose filter membranes attached to a vacuum manifold. $\left[{ }^{35} \mathrm{~S}\right]-\mathrm{GTP} \gamma \mathrm{S}$ binding to transducin was determined by scintillation counting. Because of the variability of opsin expression, experiments on a given opsin type were carried out using aliquots of membranes drawn from the same batch of COS cells and subjected to a separate analysis of variance using Stata (version 6, StataCorp, College Station, TX).

\section{Results}

\section{Identification of transducins in salamander rods} and cones

For a full evaluation of the Transducin Hypothesis, it was necessary to know which transducin was expressed in each type of photoreceptor. Rod transducin $\alpha$-subunit is present in both kinds of rods, whereas cone transducin $\alpha$-subunit is present in BS cones (Ma et al., 2001b). Here we show that RS cones and UVS cones also contained cone transducin $\alpha$-subunit (Figs. 1A to 1F). The absence of any cells doubly labeled for rod and cone transducin ruled out co-localization of the G-proteins (Figs. 1G to 1I).

\section{Effects of $\beta$-ionone on partially bleached rods and cones}

The procedure for testing the Opsin and Transducin Hypotheses is shown for a GS rod in Fig. 2. After a partial bleach of the rod's pigment, circulating current was lost, flash sensitivity decreased, and response kinetics accelerated. The same was true for every photoreceptor type; all rods and cones succumbed to pigment adaptation after partial bleaching. Pigment adaptation in GS rods was heightened by the continuous application of $\beta$-ionone (Fig. 2), consistent with Kefalov et al. (1999). Augmentation readily re-
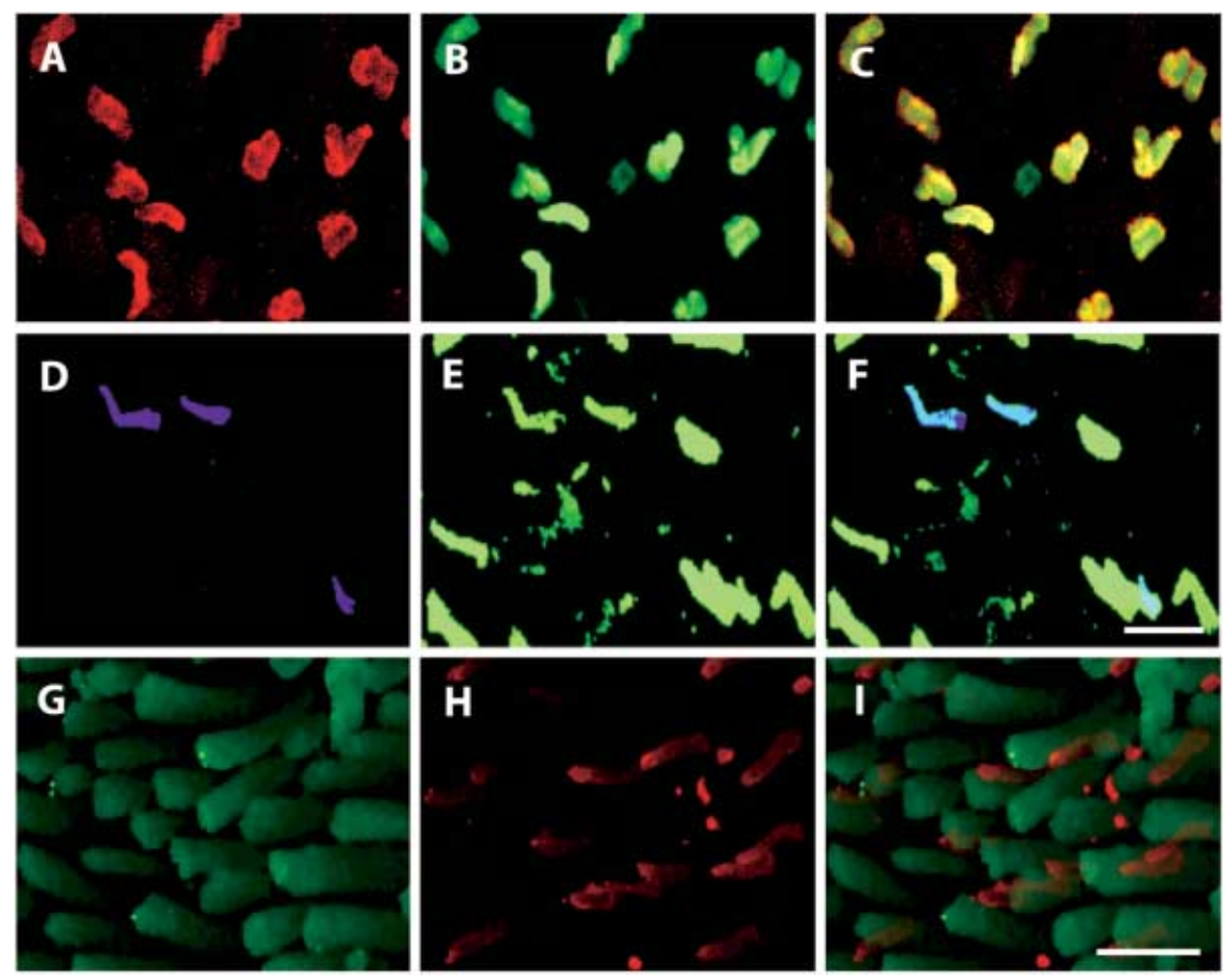

Fig. 1. Segregation of rod and cone transducins. Whole-mounted salamander retinas were immunolabeled for either RS cone (A, shown in red) or UVS cone (D, shown in purple) opsin, and cone transducin $\alpha$-subunit (shown in green, B, E). All RS cones and UVS cones were doubly labeled yellow $(\mathbf{C})$ and light blue $(\mathbf{F})$, respectively in the composites. Anti-rod transducin (G, green) and anti-cone transducin $(\mathbf{H}$, red) labeled non-overlapping populations of photoreceptors $(\mathbf{I})$. Scale bar $=16 \mu \mathrm{m}(\mathbf{A}$ to $\mathbf{F}), 40 \mu \mathrm{m}(\mathbf{G}$ to $\mathbf{I})$. 
A

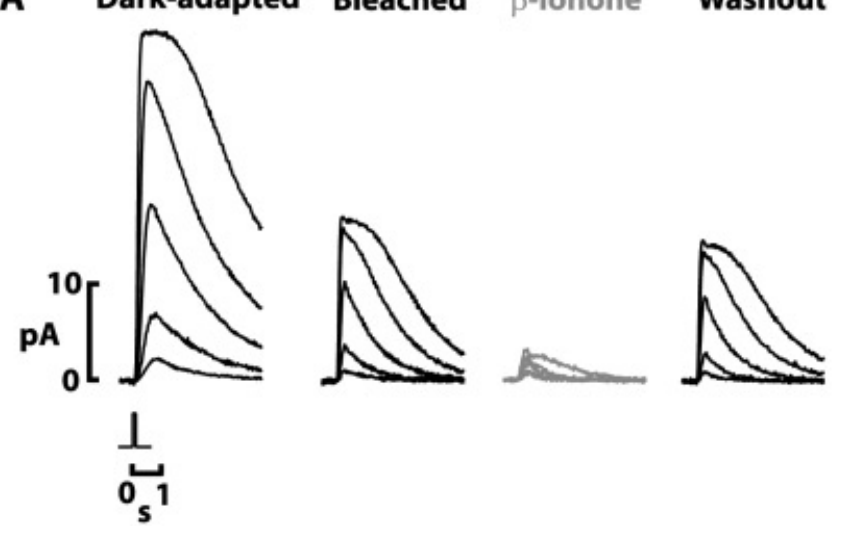

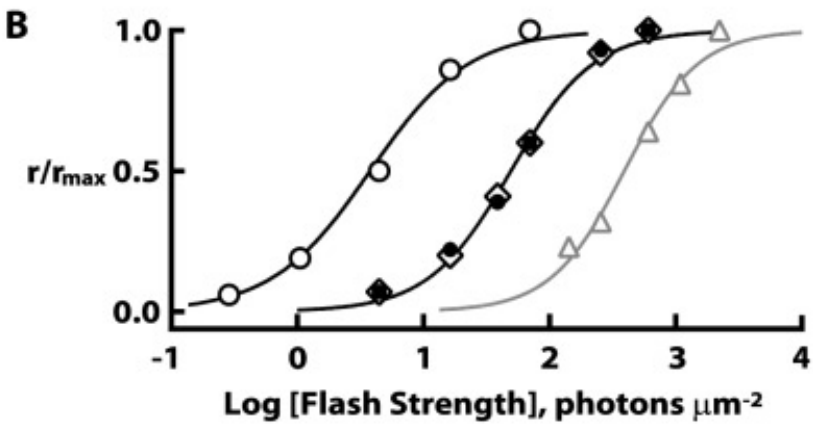

Fig. 2. Enhancement of pigment adaptation with $\beta$-ionone in a GS rod. (A) Averaged responses to $500 \mathrm{~nm}$ flashes of increasing strength from left to right: in the dark-adapted state, following a $40 \%$ pigment bleach, in the presence of $15 \mu \mathrm{M} \beta$-ionone and after washout of the $\beta$-ionone. The flash monitor is shown below the dark-adapted flash response family. The circulating current was reduced after bleaching and then reduced further during perfusion with $\beta$-ionone (gray traces). (B) Stimulus-response relations for the four conditions illustrated in A. The relations include some responses not shown in A. Responses were normalized by the maximal response recorded under each of the respective conditions and fit with Eq. (2). O, dark-adapted $\left(\mathrm{r}_{\max }=37 \mathrm{pA}\right.$; Hill coefficient $=1.1 ; \mathrm{i}_{0.5}=4$ photons $\left.\mu \mathrm{m}^{-2}\right)$;, after partial bleach $\left(\mathrm{r}_{\max }=18 \mathrm{pA}\right.$; Hill coefficient $=1.3 ; \mathrm{i}_{0.5}=49$ photons $\left.\mu \mathrm{m}^{-2}\right) ; \Delta$, during $\beta$-ionone perfusion $\left(\mathrm{r}_{\max }=3 \mathrm{pA}\right.$; Hill coefficient $=1.5 ; \mathrm{i}_{0.5}=390$ photons $\left.\mu \mathrm{m}^{-2}\right) ; \diamond$, after washout of $\beta$-ionone with Ringer's $\left(\mathrm{r}_{\max }=16 \mathrm{pA}\right.$; Hill coefficient $=1.3 ; \mathrm{i}_{0.5}=49$ photons $\mu \mathrm{m}^{-2}$ ).

versed within minutes after washing cells with Ringer's. $\beta$-Ionone had a similar effect on partially bleached BS rods (Fig. 3), which express a cone-type pigment coupled to rod transducin. These results are not consistent with the Opsin Hypothesis, but instead they support the Transducin Hypothesis.

When compared to the rods, $\beta$-ionone had the opposite effect on partially bleached RS cones; circulating current and flash sensitivity recovered partially and flash response kinetics slowed (Fig. 4; see also Jin et al., 1993). The majority of our cone experiments were carried out on single cones, but we did record from two double cones that also express RS cone pigment (Attwell et al., 1983; Sherry et al., 1998). In each case, inner segments of both members of the double cone were drawn into the suction pipette. As with single RS cones, $\beta$-ionone relieved pigment adaptation induced by partial bleaching (results not shown).

Interestingly, the circulating current was always greatest in RS cones just after initiation of perfusion with $\beta$-ionone when we often observed up to $100 \%$ recovery. When perfusion continued for $30 \mathrm{~min}$ or longer, the circulating current declined, and washout usually resulted in lower flash sensitivity and faster response kinetics than observed just prior to treatment (Figs. 5A, 5B). There was also a slow loss of response amplitude and sensitivity in
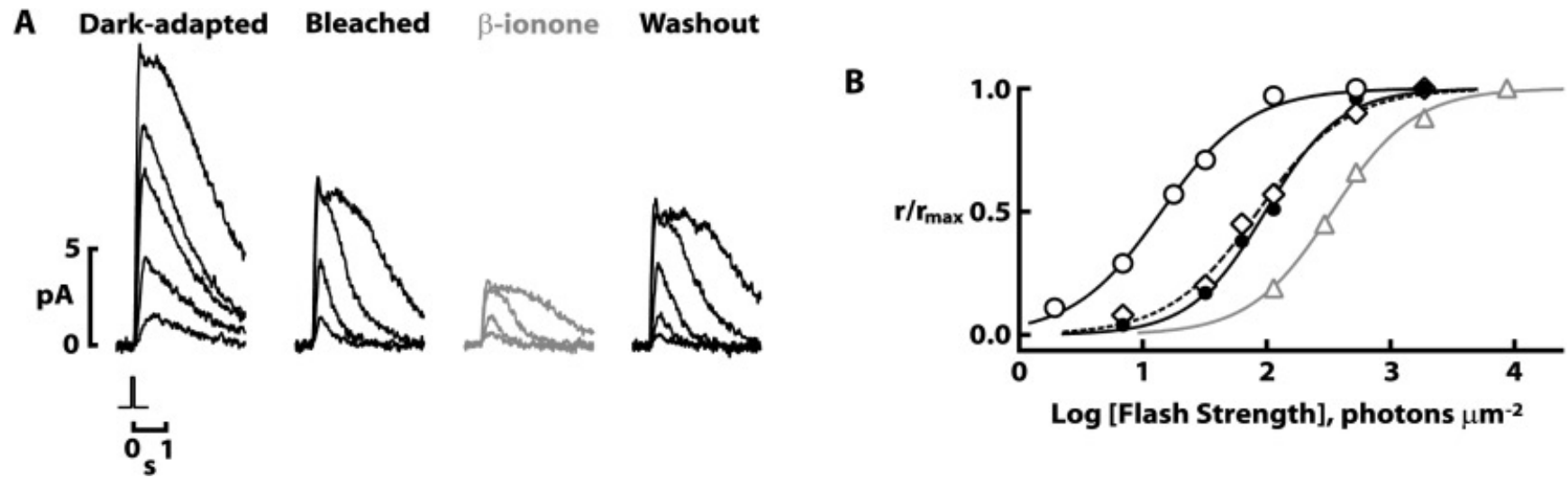

Fig. 3. Enhanced pigment adaptation by $\beta$-ionone in a BS rod. (A) Averaged responses to $440 \mathrm{~nm}$ flashes of increasing strength are shown from left to right: for the dark-adapted state, after a $13 \%$ pigment bleach, during subsequent treatment with $15 \mu \mathrm{M} \beta$-ionone and after washout of $\beta$-ionone. The circulating current decreased after bleaching and was reduced further during perfusion with $\beta$-ionone (gray traces). (B) Stimulus-response relations for the four conditions illustrated in A. Responses were normalized by the maximal response recorded under each of the respective conditions and fit with Eq. (2). O, dark-adapted $\left(\mathrm{r}_{\max }=16 \mathrm{pA}\right.$; Hill coefficient $=1.2 ; \mathrm{i}_{0.5}=14$ photons $\left.\mu \mathrm{m}^{-2}\right)$;, after partial bleach $\left(\mathrm{r}_{\max }=9 \mathrm{pA} ;\right.$ Hill coefficient $=1.4 ; \mathrm{i}_{0.5}=98$ photons $\left.\mu \mathrm{m}^{-2}\right)$; $\triangle$, during $\beta$-ionone perfusion ( $\mathrm{r}_{\max }=3 \mathrm{pA}$; Hill coefficient $=1.3 ; \mathrm{i}_{0.5}=336$ photons $\mu \mathrm{m}^{-2}$ ); after washout of $\beta$-ionone with Ringer's $\left(\mathrm{r}_{\max }=8 \mathrm{pA}\right.$; Hill coefficient $=1.2 ; \mathrm{i}_{0.5}=85$ photons $\left.\mu \mathrm{m}^{-2}\right)$. 

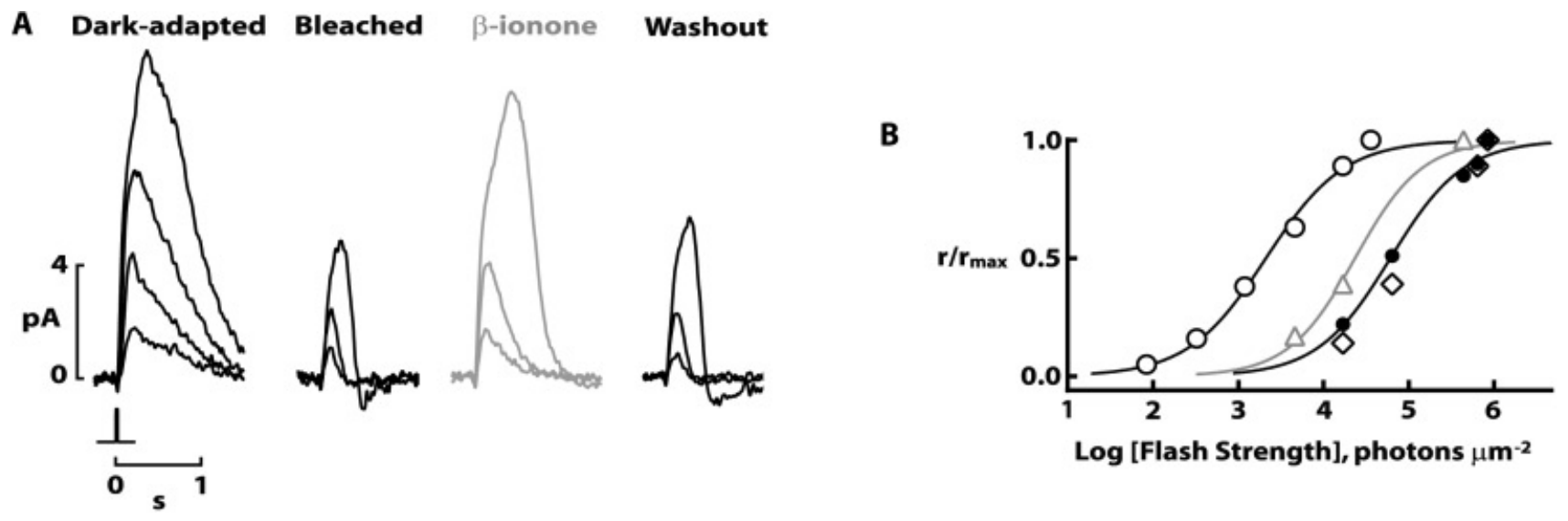

Fig. 4. Attenuation of pigment adaptation with $\beta$-ionone in a RS cone. (A) Responses to 620 nm flashes quickened and decreased in amplitude after $74 \%$ pigment bleach, but showed recovery in the presence of $6 \mu \mathrm{M} \beta$-ionone (gray traces). (B) Stimulus-response relations for the four conditions in $\mathrm{A}$, showing some recovery of sensitivity with $\beta$-ionone after partial bleach. $\mathrm{O}$, dark-adapted $\left(\mathrm{r}_{\text {max }}=\right.$ $12 \mathrm{pA}$; Hill coefficient $=0.9 ; \mathrm{i}_{0.5}=2109$ photons $\left.\mu \mathrm{m}^{-2}\right)$;, after partial bleach $\left(\mathrm{r}_{\max }=5 \mathrm{pA} ;\right.$ Hill coefficient $=1.0 ; \mathrm{i}_{0.5}=60690$ photons $\left.\mu \mathrm{m}^{-2}\right) ; \Delta$, in $\beta$-ionone $\left(\mathrm{r}_{\max }=10 \mathrm{pA}\right.$; Hill coefficient $=1.1 ; \mathrm{i}_{0.5}=23371$ photons $\mu \mathrm{m}^{-2}$ ); $\diamond$, washout of $\beta$-ionone with Ringer's $\left(\mathrm{r}_{\max }=6 \mathrm{pA} ;\right.$ Hill coefficient $=1.2 ; \mathrm{i}_{0.5}=87404$ photons $\mu \mathrm{m}^{-2}$ ).

dark-adapted RS cones during prolonged exposure to $\beta$-ionone (Figs. 5C, 5D). It would seem that $\beta$-ionone slowly displaced the native chromophore of unbleached pigment (Matsumoto et al., 1975) (Fig. 5). Thereafter, $\beta$-ionone freely exchanged within the binding pocket during perfusion because the truncated retinoid cannot form a covalent bond with opsin. The ensuing washout removed $\beta$-ionone and generated apo-opsins. So, although the immediate effect of $\beta$-ionone is to promote recovery of darkadapted physiology by occupancy of the ring recognition domain, it slowly replaced the cis retinal and created additional apo-opsins. To avoid this situation, we lowered the concentration of $\beta$-ionone applied to RS cones and restricted the time spent in retinoid to $20 \mathrm{~min}$ or less.

If the Transducin Hypothesis were true, then BS cones would respond to $\beta$-ionone in a manner similar to RS cones because both contain cone transducin. To our surprise, $\beta$-ionone enhanced pigment adaptation in BS cones, decreasing the circulating current and flash sensitivity, and accelerating flash response kinetics (Fig. 6). In five cells, the effects were even reinstated after washout by a second round of perfusion with $\beta$-ionone (e.g., Fig. 6B), confirming that the effects elicited by the retinoid were reversible and reproducible. Moreover, three partially bleached UVS cones responded to $\beta$-ionone with enhanced pigment adaptation (results not shown). Averaged results for all the different rods and cones are summarized in Table 1 and Fig. 7. The finding that all partially bleached rods and cones except for RS cones were desensitized by $\beta$-ionone argues that transducin type does not determine the identity of $\beta$-ionone as an agonist or an inverse agonist.

\section{$\beta$-Ionone activates all recombinant opsins except $R S$ cone opsin}

As a final test, recombinant salamander opsins were assayed for their ability to activate purified bovine rod transducin. There was a low level of constitutive activity for all opsins (Fig. 8). With GS rod opsin, GTP $\gamma \mathrm{S}$ binding to transducin was elevated slightly by 11-cis retinal at early time points (Fig. 8A) because of a brief period of stimulation of opsin prior to rhodopsin regeneration and full quench (Kefalov et al., 2001). Notwithstanding, the basal level of activity of each of the four opsins decreased on incubation with 11-cis retinal as shown by the decreased rates of GTP $\gamma \mathrm{S}$ binding in Fig. 8. Addition of $\beta$-ionone in place of 11-cis retinal increased GTP $\gamma \mathrm{S}$ binding for GS rod $(1.3 \pm 0.1$-fold $)$, UVS cone $[1.3 \pm$ 0.1 -fold, from Kono (2006)], and BS cone (2.0 \pm 0.04 -fold) opsins (Figs. 8A to 8C, triangles), indicating activation of opsin. Redsensitive cone opsin alone exhibited a $4.8 \pm 0.5$-fold decrease in GTP $\gamma \mathrm{S}$ binding rate in the presence of $\beta$-ionone (Fig. 8D). The use of rod transducin for all assays indicated that the variable effects of $\beta$-ionone did not require different transducins.

\section{Discussion}

The opposing effects of $\beta$-ionone on partially bleached GS rods and RS cones (Jin et al., 1993; Kefalov et al., 1999) led to an Opsin Hypothesis wherein occupancy of a portion of the chromophorebinding pocket activates rod opsin but quenches cone opsin. Yet, a Transducin Hypothesis was also plausible in which rod transducin, but not cone transducin, is activated by opsins with $\beta$-ionone. To determine whether opsin or transducin specified $\beta$-ionone as an agonist or an inverse agonist, we compared the behavior of BS rods to that of BS cones from salamander, because the two cells use the same cone-type opsin with different transducins (Ma et al., $2001 b$ ).

In single cell recordings, $\beta$-ionone activated opsin and intensified pigment adaptation in partially bleached GS rods and BS rods, consistent with the Transducin Hypothesis. But, it also had the same effect on BS cones and UVS cones. By immunofluorescence, all rods were shown to contain the rod transducin $\alpha$-subunit, all cones to contain the cone transducin $\alpha$-subunit and no photoreceptor expressed a transducin mixture. The effect of $\beta$-ionone on partially bleached cells irrespective of their transducin type argued against the Transducin Hypothesis.

Yet, we cannot completely dismiss some role for transducin type. G-protein $\beta \gamma$-subunits contribute to receptor binding (reviewed in Clapham \& Neer, 1997; Downes \& Gautam, 1999), and several $\beta$-subunits have been cloned from salamander retina (Ryan 

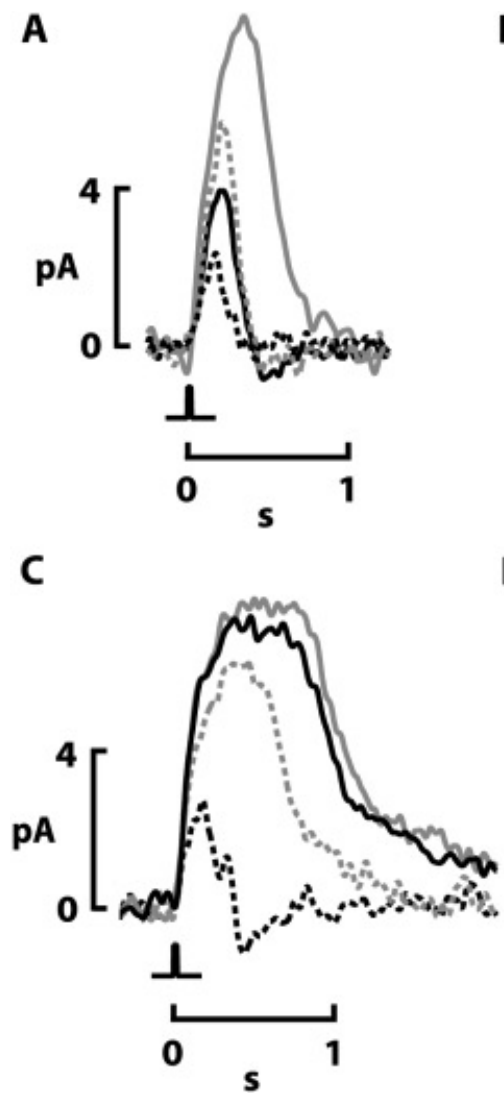

B
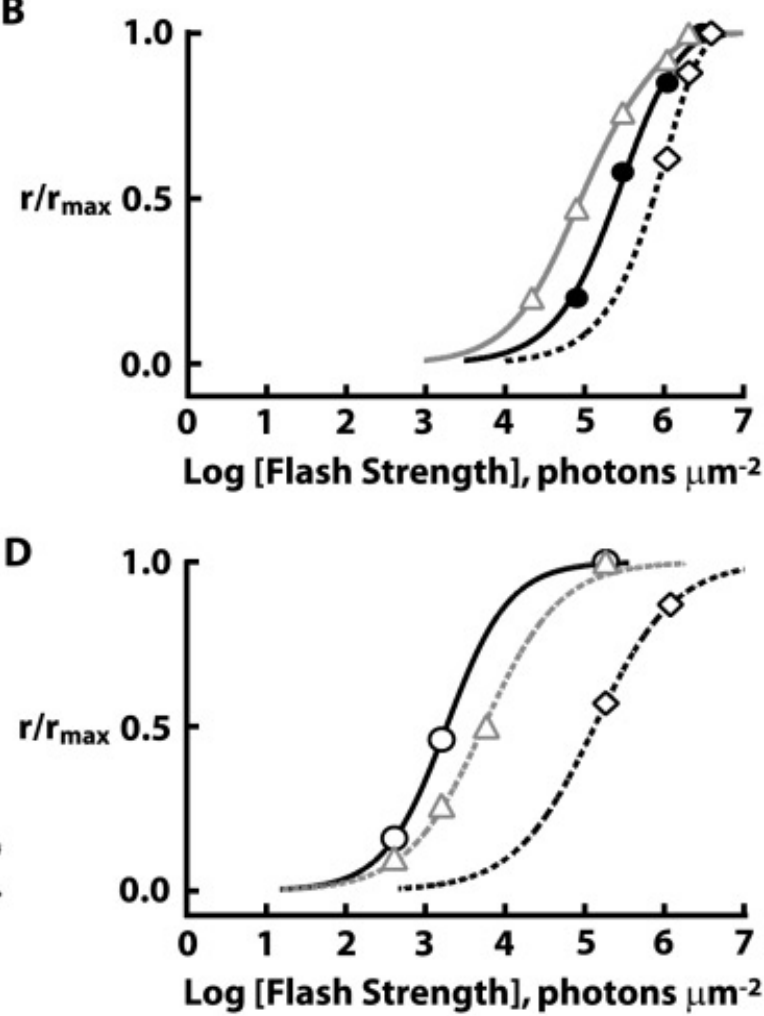

Fig. 5. Effects of prolonged exposure to $\beta$-ionone on RS cones. (A) Partial bleaching decreased response amplitude and accelerated response kinetics (solid black trace) to a saturating flash $\left(620 \mathrm{~nm} ; 3.0 \times 10^{6}\right.$ photons $\left.\mu \mathrm{m}^{-2}\right)$. Immediately after immersion in $14 \mu \mathrm{M}$ $\beta$-ionone, dark current recovered and response kinetics slowed (solid gray trace), but after a cumulative 12.5 min of perfusion in $\beta$-ionone, circulating current declined and response kinetics accelerated (dashed gray trace). Washout of $\beta$-ionone in Ringer's after $25 \mathrm{~min}$ in retinoid resulted in an additional decline in the response (dashed black trace). (B) Stimulus-response relations for the RS cone in A. When compared to the cell in Ringer's $\left(\bullet\right.$, corresponding to the solid black trace in A; $\mathrm{r}_{\max }=4 \mathrm{pA}$; Hill coefficient $=1.3 ; \mathrm{i}_{0.5}=$ 237278 photons $\left.\mu \mathrm{m}^{-2}\right)$, relative sensitivity improved threefold initially in the presence of $\beta$-ionone $(\triangle$, corresponding to the dashed gray trace in $\mathrm{A} ; \mathrm{r}_{\max }=8 \mathrm{pA}$; Hill coefficient $=1.0 ; \mathrm{i}_{0.5}=89509$ photons $\left.\mu \mathrm{m}^{-2}\right)$. After washout of the $\beta$-ionone, the flash sensitivity was reduced threefold from post-bleach values $\left(\diamond\right.$, corresponding to the dashed black trace in $\mathrm{A} ; \mathrm{r}_{\max }=2 \mathrm{pA}$; Hill coefficient $=2.6$; $\mathrm{i}_{0.5}=913779$ photons $\left.\mu \mathrm{m}^{-2}\right)$. (C) Responses to saturating flashes $\left(600 \mathrm{~nm} ; 1.9 \times 10^{5}\right.$ photons $\left.\mu \mathrm{m}^{-2}\right)$ for a dark-adapted double cone were similar in amplitude and kinetics whether measured in Ringer's (solid black trace) or measured during the first few minutes of perfusion with $17 \mu \mathrm{M} \beta$-ionone (solid gray trace). Following $25 \mathrm{~min}$ of perfusion with $\beta$-ionone, the response to the same $600 \mathrm{~nm}$ flash decreased in amplitude and its recovery kinetics accelerated (dashed gray line). These changes became more pronounced upon return of the cell to Ringer's after a total period of exposure to $\beta$-ionone for $35 \mathrm{~min}$ (dashed black line). (D) Stimulus-response relations for the cell in C. Relative sensitivity decreased 3-fold after $>25 \mathrm{~min}$ in $\beta$-ionone ( $\triangle$, corresponding to the dashed gray trace in $\mathrm{C}$; $\mathrm{r}_{\max }=6 \mathrm{pA}$; Hill coefficient $=0.9 ; \mathrm{i}_{0.5}=5407$ photons $\left.\mu \mathrm{m}^{-2}\right)$ compared to that in Ringer's $(\mathrm{O}$, corresponding to solid black trace in $\mathrm{C} ; \mathrm{r}_{\max }=8 \mathrm{pA}$; Hill coefficient $=1.1 ; \mathrm{i}_{0.5}=1846$ photons $\mu \mathrm{m}^{-2}$ ). After washout of the $\beta$-ionone, the flash sensitivity was reduced 70-fold $\left(\diamond\right.$, corresponding to the dashed black trace in $\mathrm{C} ; \mathrm{r}_{\max }=3 \mathrm{pA}$; Hill coefficient $=0.9 ; \mathrm{i}_{0.5}=133604$ photons $\mu \mathrm{m}^{-2}$ ).

et al., 2001). At present, the pattern of cellular expression is known only for the transducin $\alpha$-subunit. A complete rejection of the Transducin Hypothesis must therefore await the characterization of transducin $\beta$ - and $\gamma$-subunits in salamander photoreceptors.

All-trans retinal and $\beta$-ionone induce phosphorylation of GS rod opsin and binding to arrestin, reducing opsin's ability to activate transducin (Craft et al., 1994; Nir \& Ransom, 1992; Sakuma et al., 1996; Smith et al., 2000) and in some species, distinct pigment kinases (Hisatomi et al., 1998; Weiss et al., 1998, 2001). Retinoids also inhibit cyclic nucleotide-gated channels (Dean et al., 2002), which could effect circulating current, but $\beta$-ionone is a poor channel inhibitor (Horrigan et al., 2005) making this interaction an unlikely source for its effects.
Assays using recombinant salamander rod and cone opsins and purified bovine rod transducin in a reconstituted system verified that $\beta$-ionone promoted GTP exchange on rod transducin by all opsins, except RS cone opsin for which it had the opposite effect. This result ruled out a mechanism requiring photoreceptor typespecific expression of different transducins or other phototransduction proteins such as rhodopsin kinase and arrestin. So whereas a role for other phototransduction components in retinoid modulation of pigment adaptation remains to be explored, the overall profile of $\beta$-ionone's effects on bleached photoreceptors could be explained simply in terms of structural differences across opsins. The Opsin Hypothesis in its original form, however, must be modified because a generalized distinction between rod and cone 
A Dark-adapted Bleached $\beta$-ionone

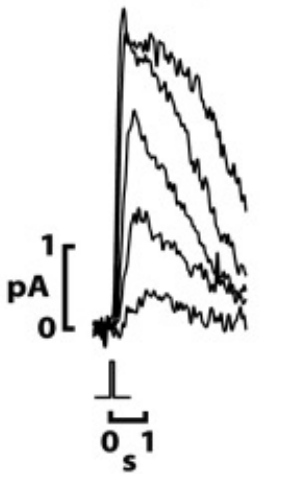

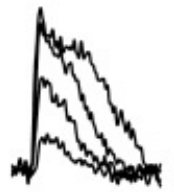

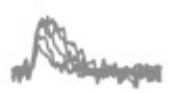

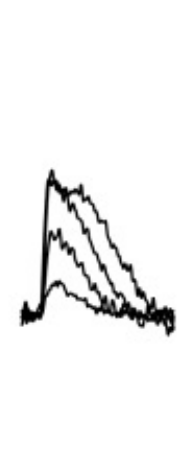

\section{Washout}

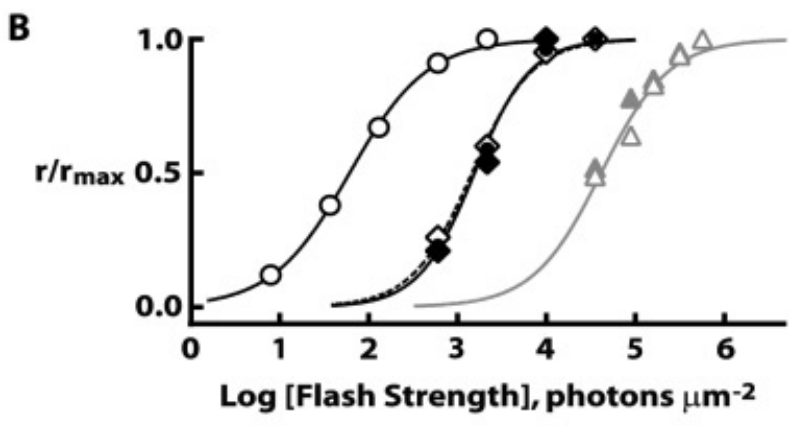

Fig. 6. Enhanced pigment adaptation by $\beta$-ionone in a BS cone. (A) Responses to $440 \mathrm{~nm}$ flashes were progressively smaller and faster after $86 \%$ pigment bleach and during exposure to $17 \mu \mathrm{M} \beta$-ionone. The effects of $\beta$-ionone reversed after washing the cell with Ringer's. (B) Further loss of sensitivity after bleaching with $\beta$-ionone for the BS cone in A. Stimulus-response relations include a second exposure to $\beta$-ionone and washout $\left(\boldsymbol{\Delta}\right.$ and $\bullet$, respectively) not shown in flash responses. $\bigcirc$, dark-adapted $\left(\mathrm{r}_{\max }=4 \mathrm{pA}\right.$; Hill coefficient $=1.0 ; \mathrm{i}_{0.5}=61$ photons $\left.\mu \mathrm{m}^{-2}\right) ; \bullet$, after partial bleach $\left(\mathrm{r}_{\max }=2 \mathrm{pA}\right.$; Hill coefficient $=1.4 ; \mathrm{i}_{0.5}=1551$ photons $\left.\mu \mathrm{m}^{-2}\right)$; $\triangle$, first exposure to $\beta$-ionone ( $\mathrm{r}_{\max }=1 \mathrm{pA}$; Hill coefficient $=1.1 ; \mathrm{i}_{0.5}=41130$ photons $\left.\mu \mathrm{m}^{-2}\right) ; \diamond$, first washout $\left(\mathrm{r}_{\max }=2 \mathrm{pA} ;\right.$ Hill coefficient $=1.3 ; \mathrm{i}_{0.5}=1457$ photons $\mu \mathrm{m}^{-2}$ ).

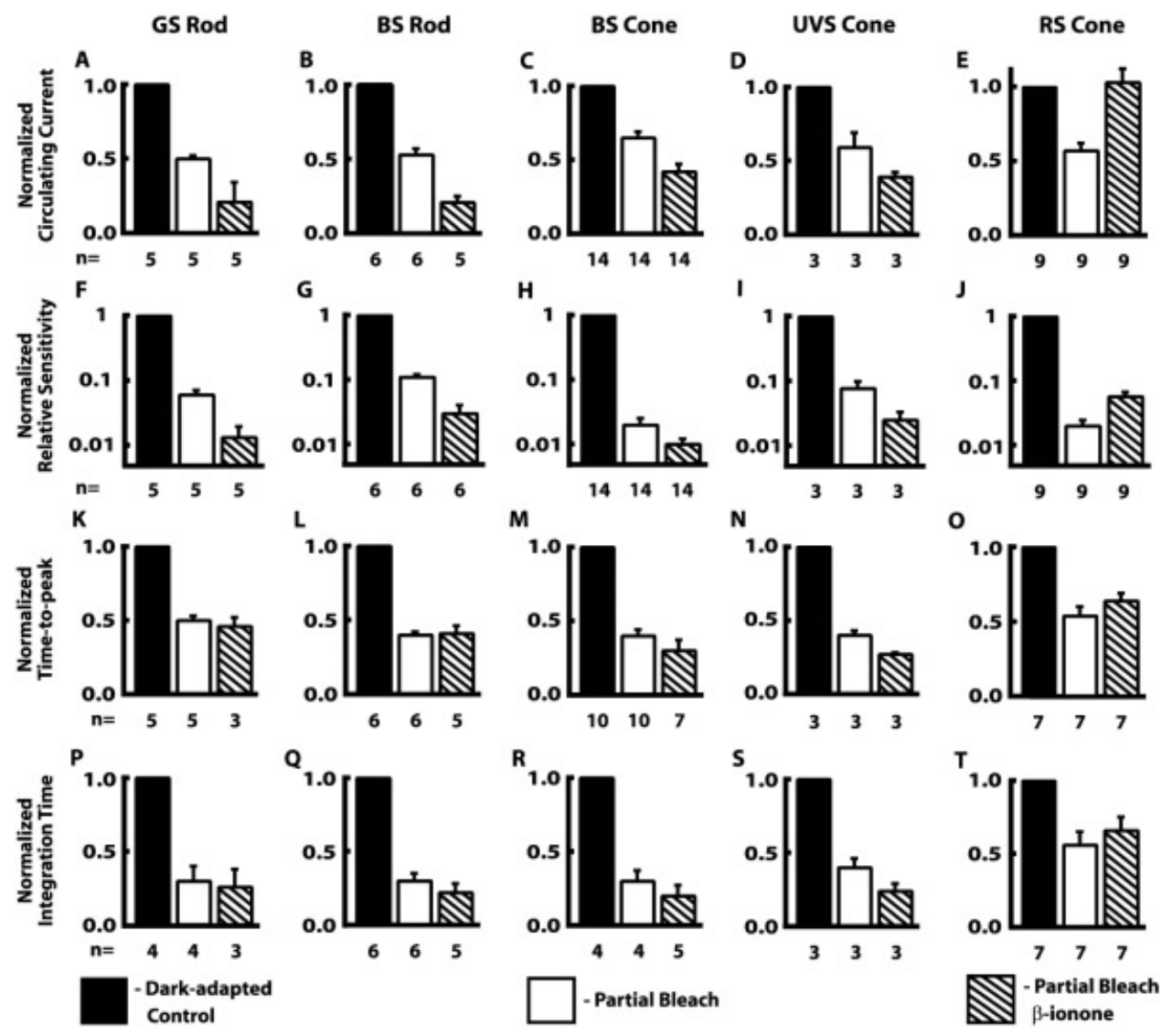

Fig. 7. Effects of partial bleaching and $\beta$-ionone on flash responses of rods and cones. Measures after partial bleach (white bars) and subsequent exposure to $\beta$-ionone (hatched bars) for (from left to right): GS rods, BS rods, BS cones, UVS cones, and RS cones. Circulating current (A to $\mathbf{E}$ ), relative sensitivity $(\mathbf{F}$ to $\mathbf{J})$, time-to-peak ( $\mathbf{K}$ to $\mathbf{O})$, and integration time $(\mathbf{P}$ to $\mathbf{T})$ were normalized to the dark-adapted control values (black bars). The ratios represented by the graphs and the parameters given in Table 1 characterize the same cells under the three conditions: dark-adapted, after partial bleaching and during subsequent treatment with $\beta$-ionone. Cells were bleached to reduce the circulating current by $30 \%$ to $50 \%$ resulting in 43 (GS rod), 16 (BS rod), 73 (BS cone), 20 (UVS cone), and 96 (RS cone) \% pigment bleached on average per cell type. All parameters decreased upon partial bleach. Exposure to $\beta$-ionone accentuated pigment adaptation in all cells except RS cones, for which pigment adaptation was relieved. Percent pigment bleached was calculated as described in Methods. Error bars are \pm SEM. 
Table 1. Flash response parameters for dark-adapted rods and cones. Values are given as mean $\pm S E M, n . r_{\text {max }}$, the response amplitude for a saturating flash, provides a measure of the circulating current. $i_{0.5}$ characterizes sensitivity; it is the flash strength that gives rise to a half-maximal response at the wavelength to which the cell is most sensitive. Kinetic parameters are given for dim flash responses, whose amplitudes were $\leq 0.15 r_{\max }$. Dim flash responses have the same shape as the single photon response. Time-to-peak, $t_{p}$, was taken as the interval from mid-flash to the peak of the dim flash response, and integration time, $T_{i}$, as the response integral divided by response amplitude. Values for $R S$ cone do not include results from double cones or from experiments with long exposures to high concentrations of $\beta$-ionone.

\begin{tabular}{lcclc}
\hline \hline Cell Type & $\mathrm{r}_{\max }, \mathrm{pA}$ & $\begin{array}{c}\mathrm{i}_{0.5}, \\
\text { photons } \mu \mathrm{m}^{-2}\end{array}$ & \multicolumn{1}{c}{$\mathrm{t}_{\mathrm{p}}, \mathrm{ms}$} & $\mathrm{T}_{\mathrm{i}}, \mathrm{ms}$ \\
\hline GS rod & $24 \pm 3,5$ & $5 \pm 1,5$ & $696 \pm 64,5$ & $5660 \pm 3470,4$ \\
BS rod & $16 \pm 3,6$ & $12 \pm 1,6$ & $581 \pm 37,6$ & $3710 \pm 2180,6$ \\
RS cone & $9 \pm 1,9$ & $1860 \pm 240,9$ & $166 \pm 8,7$ & $244 \pm 29,7$ \\
BS cone & $8 \pm 1,14$ & $121 \pm 22,14$ & $559 \pm 56,10$ & $1750 \pm 370,4$ \\
UVS cone & $8 \pm 1,3$ & $510 \pm 252,3$ & $375 \pm 29,3$ & $880 \pm 180,3$
\end{tabular}

\section{A}
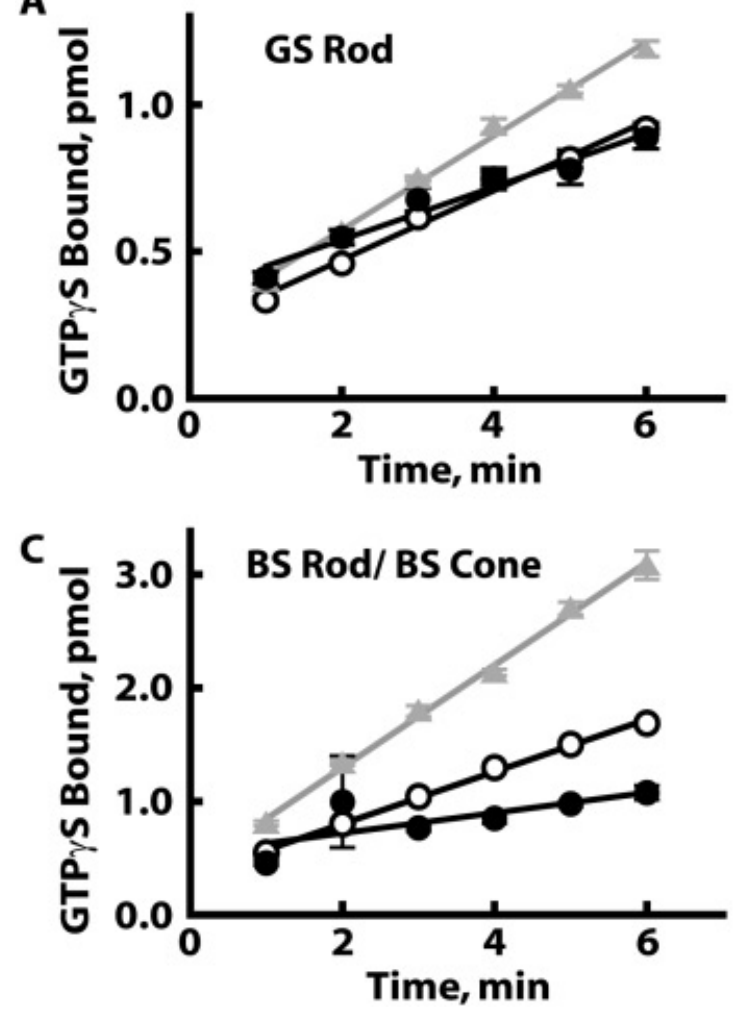

pigments is not warranted. Rather, a division between RS cone opsin and all other opsins is more appropriate.

The molecular characteristics underlying the unique response of the RS cone to $\beta$-ionone are unknown, but two distinctive features of RS cone opsins may provide clues. Vertebrate GS rod opsins possess a highly conserved pair of cysteines on the carboxy terminus (Pittler et al., 1992), to which palmitates are attached (Ovchinnikov et al., 1988), and insertion of the palmitates into the membrane leads to the formation of a fourth cytoplasmic loop (Moench et al., 1994a; 1994b). Removal of both palmitates from bovine rhodopsin reduces the ability of all-trans retinal to activate opsin, which is restored upon re-palmitoylation (Sachs et al., 2000). All salamander cone opsins retain one of the cysteines on their carboxy terminal tails except RS cone opsin (Chen et al., 1996; Xu et al., 1998; Ma et al., 2001a). Perhaps the presence of a fourth loop is a prerequisite for pharmacologic activation with $\beta$-ionone.

Second, the RS cone visual pigment has higher rates of spontaneous dissociation into opsin and chromophore (Kefalov et al., 2005) and thermal activation of the phototransduction cascade (Rieke \& Baylor, 2000) than pigments formed from GS rod or BS cone opsins. The gradual desensitization of both partially bleached and dark-adapted $\mathrm{RS}$ cones in the presence of $\beta$-ionone is a
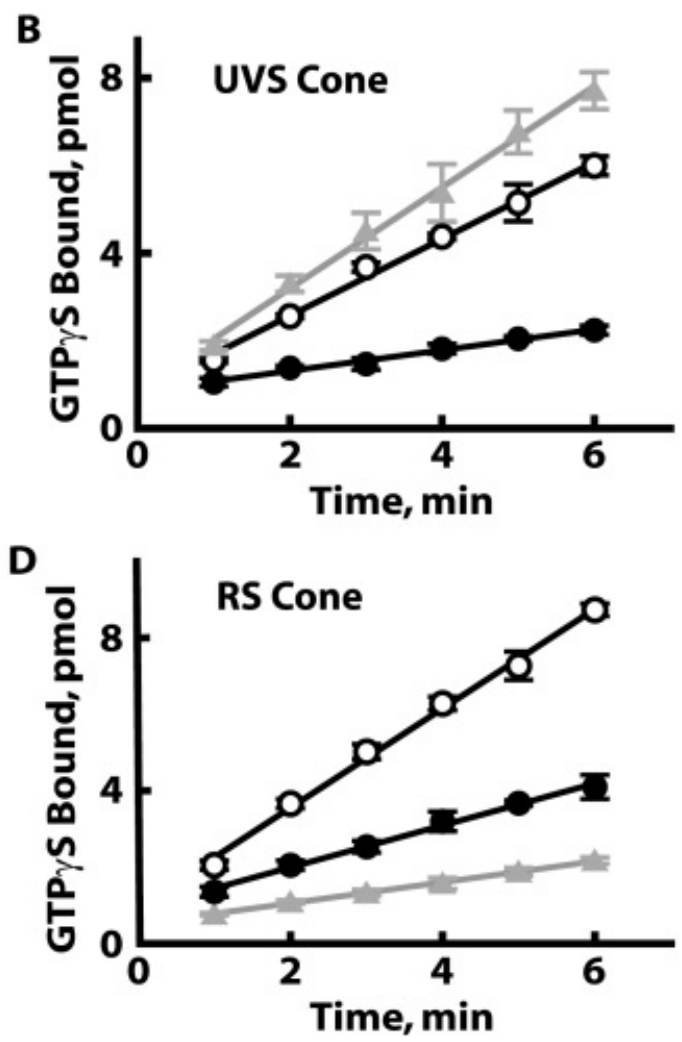

Fig. 8. Effects of $\beta$-ionone on the activation of recombinant salamander (A) GS rod, (B) UVS cone, (C) BS rod/BS cone, and (D) RS cone opsins. The rate of opsin-stimulated $\left[{ }^{35} \mathrm{~S}\right]-\mathrm{GTP} \gamma \mathrm{S}$ uptake by transducin, given by the slope of the line through the points $(\mathrm{O})$, decreased after pigment regeneration with 11-cis retinal, $\bullet ; p<0.008$ for each opsin type by ANOVA, followed by a Scheffe test. Addition of $100 \mu \mathrm{M} \beta$-ionone to opsin, $\Delta$, increased the rate of $\left[{ }^{35} \mathrm{~S}\right]$-GTP $\gamma \mathrm{S}$ binding to transducin for all opsins, except the RS cone opsin, where there was a decreased rate (panel $\mathbf{D}, p<0.001$ ). Error bars are \pm SEM, $n=4$ for assays with BS rod/BS cone opsin, $n=3$ for assays with all other opsins. The data for the UVS cone opsin alone and with 11-cis retinal are reprinted with permission from the Federation of the European Biochemical Societies 
reflection of the inherent instability of its pigment. The chromophorebinding pocket of RS cone opsin contains several hydroxylbearing amino acids that tune the pigment to longer wavelengths (reviewed in Yokoyama, 2000). If in addition to spectral tuning, pigment instability resulted from the presence of these hydroxyl groups, then quench of bleached RS cone opsin by the chromophore ring may have been a necessary compensation to prevent excessive loss of flash sensitivity prior to regeneration. Functional differences between rod and cone pigments have long been appreciated, but our study adds to a growing body of evidence revealing important differences across cone pigments beyond their spectral absorptions, and will guide future work into their structural bases.

\section{Acknowledgments}

The authors thank M.C. Cornwall and A.L. Zimmerman for helpful discussions. This work was supported by NEI EY11358 (CLM), EY04939 (RKC), EY014793 (RKC), EY12231 (JXM), EY15650 (JXM), EY013748 (MK), EY014104 (core grant to MEEI), and an unrestricted grant to MUSC from Research to Prevent Blindness, Inc. RKC is an RPB Senior Scientific Investigator.

\section{References}

Attwell, D.I., Werblin, F.S., Wilson, M. \& Wu, S.M. (1983). Properties of double cones in the larval salamander retina. Journal of Physiology (London) 341, 74.

Baehr, W., Morita, E.A., Swanson, R.J. \& Applebury, M.L. (1982). Characterization of bovine rod outer segment G-protein. Journal of Biological Chemistry 257, 6452-6460.

Chen, N., Ma, J.-X., Corson, D.W., Hazard, E.S. \& Crouch, R.K. (1996). Molecular cloning of a rhodopsin gene from salamander rods. Investigative Ophthalmology and Visual Science 37, 1907-1913.

Clapham, D.E. \& Neer, E.J. (1997). G protein $\beta \gamma$ subunits. Annual Review of Pharmacology and Toxicology 37, 167-203.

Corson, D.W., Kefalov, V.J., Cornwall, M.C. \& Crouch, R.K. (2000). Effect of 11-cis 13-demethylretinal on phototransduction in bleachadapted rod and cone photoreceptors. Journal of General Physiology 116, 283-297.

Craft, C.M., Whitmore, D.H. \& Weichmann, A.F. (1994). Cone arrestin identified by targeting expression of a functional family. Journal of Biological Chemistry 269, 4613-4619.

Das, J., Crouch, R.K., MA, J.-X., Oprian, D.D. \& Kono, M. (2004). Role of the 9-methyl group of retinal in cone visual pigments. Biochemistry 43, 5532-5538.

Dean, D.M., Nguitragool, W., Miri, A., McCabe, S.L. \& Zimmerman, A.L. (2002). All-trans-retinal shuts down rod cyclic nucleotide-gated ion channels: A novel role for photoreceptor retinoids in the response to bright light? Proceedings of the National Academy of Science USA 99, 8372-8377.

Downes, G.B. \& Gautam, N. (1999). The G protein subunit gene families. Genomics 62, 544-552.

Ebrey, T. \& Koutalos, Y. (2001). Vertebrate photoreceptors. Progress in Retinal and Eye Research 20, 49-94.

Fain, G.L., Matthews, H.R., Cornwall, M.C. \& Koutalos, Y. (2001). Adaptation in vertebrate photoreceptors. Physiological Reviews 81, 117-151.

Fung, B.K.-K., Lieberman, B.S. \& Lee, R.H. (1992). A third form of the $\mathrm{G}$ protein $\beta$ subunit. 2. Purification and biochemical properties. Journal of Biological Chemistry 267, 24782-24788.

Hisatomi, O., Matsuda, S., Satoh, T., Kotaka, S., Imanishi, Y. \& ToKunaga, F. (1998). A novel subtype of G-protein-coupled receptor kinase, GRK7, in teleost cone photoreceptors. Federation of European Biochemical Societies Letters 424, 159-164.

Horrigan, D.M., Tetreault, M.L., Tsomaia, N., Vasileiou, C., Borhan, B., Mierke, D.F., Crouch, R.K. \& Zimmerman, A.L. (2005). Defining the retinoid binding site in the rod cyclic nucleotide-gated channel. Journal of General Physiology 126, 453-460.

Jin, J., Crouch, R.K., Corson, D.W., Katz, B.M., MacNichol, E.F. \& Cornwall, M.C. (1993). Noncovalent occupancy of the retinal- binding pocket of opsin diminishes bleaching adaptation of retinal cones. Neuron 11, 513-522.

Jones, G.J., Crouch, R.K., Wiggert, B., Cornwall, M.C. \& Chader, G.J. (1989). Retinoid requirements for recovery of sensitivity after visual-pigment bleaching in isolated photoreceptors. Proceedings of the National Academy of Science USA 86, 9606-9610.

Kefalov, V.J., Cornwall, M.C. \& Crouch, R.K. (1999). Occupancy of the chromophore binding site of opsin activates visual transduction in rod photoreceptors. Journal of General Physiology 113, 491-503.

Kefalov, V.J., Crouch, R.K. \& Cornwall, M.C. (2001). Role of noncovalent binding of 11-cis-retinal to opsin in dark adaptation of rod and cone photoreceptors. Neuron 29, 749-755.

Kefalov, V.J., Estevez, M.E., Kono, M., Goletz, P.W., Crouch, R.K., Cornwall, M.C. \& YAU, K.-W. (2005). Breaking the covalent bond-A pigment property that contributes to desensitization in cones. Neuron 46, 879-890.

Kono, M. (2006). Constitutive activity of a UV cone opsin. Federation of European Biochemical Societies Letters 580, 229-232.

Lee, R.H., Lieberman, B.S., Yamane, H.K., BoK, D. \& Fung, B.K.-K. (1992). A third form of the $\mathrm{G}$ protein $\beta$ subunit. 1. Immunochemical identification and localization to cone photoreceptors. Journal of Biological Chemistry 267, 24776-24781.

Ma, J.-X., Kono, M., Xu, L., Das, J., Ryan, J.C., Hazard, E.S. III, Oprian, D.D. \& CROUCH, R.K. (2001a). Salamander UV cone pigment: Sequence, expression, and spectral properties. Visual Neuroscience 18, 393-399.

Ma, J.-X., Znoiko, S., Othersen, K.L., Ryan, J.C., Das, J., Isayama, T., Kono, M., Oprian, D.D., Corson, D.W., Cornwall, M.C., Cameron, D.A., Harosi, F.I., Makino, C.L. \& Crouch, R.K. (2001b). A visual pigment expressed in both rod and cone photoreceptors. Neuron 32, 451-461.

MaKino, C.L. \& Dodd, R.L. (1996). Multiple visual pigments in a photoreceptor of the salamander retina. Journal of General Physiology 108, 27-34.

Makino, C.L., Groesbeek, M., Lugtenburg, J. \& Baylor, D.A. (1999). Spectral tuning in salamander visual pigments studied with dihydroretinal chromophores. Biophysical Journal 77, 1024-1035.

Makino, C.L., TAYLOR, W.R. \& BAYLOR, D.A. (1991). Rapid charge movements and photosensitivity of visual pigments in salamander rods and cones. Journal of Physiology (London) 442, 761-780.

Matsumoto, H., Tokunaga, F. \& Yoshizawa, T. (1975). Accessibility of the iodopsin chromophore. Biochimica et Biophysica Acta 404, 300-308.

McBee, J.K., Palczewski, K., Baehr, W. \& Pepperberg, D.R. (2001). Confronting complexity: The interlink of phototransduction and retinoid metabolism in the vertebrate retina. Progress in Retinal and Eye Research 20, 469-529.

Moench, S.J., Terry, C.E. \& Dewey, T.G. (1994a). Fluoresence labeling of the palmitoylation sites of rhodopsin. Biochemistry 33, 5783-5790.

Moench, S.J., Moreland, J., Stewart, D.H. \& Dewey, T.G. (1994b). Fluorescence studies of the location and membrane accessibility of the palmitoylation sites of rhodopsin. Biochemistry 33, 5791-5796.

Nir, I. \& Ransom, N. (1992). S-antigen in rods and cones of the primate retina: Different labeling patterns are revealed with antibodies directed against specific domains in the molecule. Journal of Histochemistry and Cytochemistry 40, 343-352.

Ong, O.C., Yamane, H.K., Phan, K.B., Fong, H.K.W., BoK, D., Lee, R.H. \& FUNG, B.K.-K. (1995). Molecular cloning and characterization of the G protein $\gamma$ subunit of cone photoreceptors. Journal of Biological Chemistry 270, 8495-8500.

Ovchinnikov, Y.A., Abdulaev, N.G. \& Bogachuk, A.S. (1988). Two adjacent cysteine residues in the C-terminal cytoplasmic fragment of bovine rhodopsin are palmitylated. Federation of European Biochemical Societies Letters 230, 1-5.

Peng, Y.-W., Robishaw, J.D., Levine, M.A. \& YaU, K.-W. (1992). Retinal rods and cones have distinct $\mathrm{G}$ protein $\beta$ and $\gamma$ subunits. Proceedings of the National Academy of Science USA 89, 10882-10886.

Pittler, S.J., Fliesler, S.J. \& BAeHr, W. (1992). Primary structure of frog rhodopsin. Federation of European Biochemical Societies Letters 313, $103-108$.

RieKe, F. \& BAYLOR, D.A. (2000). Origin and functional impact of dark noise in retinal cones. Neuron 26, 181-186.

RoBInson, P.R. (2000). Assays for detection of constitutively active opsins. Methods in Enzymology 315, 207-218.

Robinson, P.R., CoHen, G.B., ZhuKovsky, E.A. \& OpRian, D.D. (1992). Constitutively active mutants of rhodopsin. Neuron 9, 719-725. 
Ryan, J.C., Znoiko, S., Xu, L., Crouch, R.K. \& Ma, J.-X. (2000). Salamander rods and cones contain distinct transducin alpha subunits. Visual Neuroscience 17, 847-854.

Ryan, J.C., Crouch, R.K. \& MA, J.-X. (2001). Cloning and characterization of three salamander retinal G-protein beta subunits. Molecular Vision 7, 222-227.

Sachs, K., Maretzki, D., Meyer, C.K. \& Hofmann, K.P. (2000). Diffusible ligand all-trans-retinal activates opsin via a palmitoylationdependent mechanism. Journal of Biological Chemistry 275, 6189-6194.

Sakuma, H., Inana, G., Murakami, A., Higashide, T. \& Mclaren, M.J. (1996). Immunolocalization of X-arrestin in human cone photoreceptors. Federation of European Biochemical Societies Letters 382, 105-110.

Sherry, D.M., BuI, D.D. \& DeGrIP, W.J. (1998). Identification and distribution of photoreceptor subtypes in the neotenic tiger salamander retina. Visual Neuroscience 15, 1175-1187.

Smith, W.C., Gurevich, E.V., Dugger, D.R., Vishnivetskiy, S.A., Shelamer, C.L., McDowell, J.H. \& Gurevich, V.V. (2000). Cloning and functional characterization of salamander rod and cone arrestins. Investigative Ophthalmology and Visual Science 41, 2445-2455.

VISSERS, P.M.A.M. \& DeGrIP, W.J. (1996). Functional expression of human cone pigments using recombinant baculovirus: Compatibility with histidine tagging and evidence for $N$-glycosylation. Federation of European Biochemical Societies Letters 396, 26-30.

Weiss, E.R., Raman, D., Shirakawa, S., Ducceschi, M.H., Bertram, P.T., Wong, F., Kraft, T.W. \& Osawa, S. (1998). The cloning of GRK7, a candidate cone opsin kinase, from cone- and rod-dominant mammalian retinas. Molecular Vision 4, 27-34.

Weiss, E.R., Ducceschi, M.H., Horner, T.J., Li, A., Craft, C.M. \& Osawa, S. (2001). Species-specific differences in expression of G-protein-coupled receptor kinase (GRK) 7 and GRK1 in mammalian cone photoreceptor cells: Implications for cone cell phototransduction. Journal of Neuroscience 21, 9175-9184.

WeSsLING-Resnick, M. \& Johnson, G.L. (1987). Allosteric behavior in transducin activation mediated by rhodopsin. Initial rate analysis of guanine nucleotide exchange. Journal of Biological Chemistry 262, 3697-3705.

Xu, L., Hazard, E.S. III, Lockman, D.K., Crouch, R.K. \& Ma, J.-X. (1998). Molecular cloning of the salamander red and blue cone visual pigments. Molecular Vision 4, 10-15.

YoKоYAмa, S. (2000). Molecular evolution of vertebrate visual pigments. Progress in Retinal and Eye Research 19, 385-419. 